\title{
A REFORMA PREVIDENCIÁRIA NO GOVERNO
}

LULA

\author{
Paulo Fernando Mohn e Souza*
}

\section{Introdução}

A Constituição Federal de 1988 integrou as áreas de previdência, saúde e assistência sob a rubrica da seguridade social, para consolidar mecanismos de financiamento e estabelecer um modelo de gestão capaz de tratar as especificidades de cada área, mas manter um espírito geral de proteção universal, democrática, distributiva e não-estigmatizadora (VIANNA, 1999). Entretanto, essa integração jamais ocorreu, efetivamente, por diversas razões. Entre elas, destaca-se a conjuntura político-econômica de recessão, déficit público, inflação e crise fiscal. Com isso, as agências multilaterais de crédito passaram a demandar o enxugamento do Estado e sua retração na oferta de benefícios e serviços coletivos.

As políticas de saúde, assistência e previdência social tomaram caminhos apartados. Para Monteiro Neto (2003, p. 223), a separação entre previdência e assistência social ajuda a dimensionar os problemas e permite à sociedade estabelecer com mais clareza suas prioridades. Isso porque, afirma, na previdência os participantes pagam para ter acesso aos benefícios, enquanto na assistência social os benefícios são oferecidos sem contrapartida àqueles de menor capacidade contributiva, inclusive para oferecer-lhes renda mínima.

O isolamento da previdência social embute uma perspectiva de reforço ao modelo de seguros que sustentou sua origem. Em sentido contrário, considerá-la de forma integrada à seguridade social significaria reconhecê-la, para além de um seguro individual, como uma política social, como uma parte integrante de um sistema de proteção social. Acrescenta Soares (2003, p. 118) que esse sistema de proteção social seria mais amplo e inclusivo, no qual os benefícios fossem universalizados e superassem a visão securitária da equivalência contributiva, para adotá-la não só conforme a contribuição, mas também de acordo com a

\footnotetext{
* Consultor legislativo do Senado Federal, na área de Direito Constitucional, Administrativo e Eleitoral. Bacharel em Direito e em Administração de Empresas. Pós-graduado em Direito Público, pelo Instituto Brasiliense de Direito Público (IDP). Mestrando do Programa de Mestrado em Direito do UniCEUB, área de concentração Direito e Políticas Públicas. E-mail: mohn@senado.gov.br
} 
necessidade. Desse modo, um sistema baseado no seguro apenas serviria para reproduzir a profunda desigualdade do mercado de trabalho em termos de oportunidades e salários, além de excluir quem não conseguisse inserir-se no mercado formal. Contudo, Boschetti (2003, p. 27) observa que, depois de decorrida mais de década e meia da promulgação da Constituição Federal de 1988, a seguridade social ainda não havia sido implementada como nela concebida, e as políticas que a integram continuavam a ser executadas de forma autônoma e desvinculada.

Fato é que a previdência transformou-se em um dos grandes motes das chamadas reformas estruturais, a partir da década de 1990 e nunca foi discutida, no âmbito das reformas constitucionais, de modo integrado à perspectiva da seguridade social. Desde a Reforma conduzida no decorrer do primeiro mandato Governo do Presidente Fernando Henrique Cardoso, por meio da Emenda Constitucional $n^{0} 20$, de 1998, verifica-se a tendência de restringir a seguridade social à sua dimensão previdenciária.

Vianna (1999, 1976) identifica entre "as armas do abate" da seguridade social a despolitização do debate sobre o tema, que enfoca a questão apenas pelo viés técnico e superdimensiona os aspectos fiscais e demográficos. Com isso, o Estado imprime caráter especializado à política pública previdenciária, cujo debate apresenta controvérsia e baixo grau de consenso entre os interessados, gerando decisões aparentemente neutras. Nisso, ficam desprezadas as vertentes da integração social, da solidariedade e do bem-estar. A previdência social assume posição destacada, nesse caso, não só pelo volume dos recursos envolvidos, mas também pelos interesses que em torno dela se articulam. Os usuários da assistência social e da saúde pública não têm condição de vocalização de suas demandas, não constituem grupos de pressão. Ao contrário, os interesses na previdência social envolvem não só aposentados e pensionistas, mas também sindicatos, federações e confederações patronais e dos trabalhadores, centrais sindicais, empregados, servidores públicos e, mais recentemente, os poderosos fundos de pensão.

Para Miranda (1999, p. 137), a discussão em torno da previdência tem sido palco de enormes confusões, algumas vezes involuntárias, outras deliberadas, tanto assim que, por vezes, "tenta-se apresentar o assunto como uma questão meramente técnica em que a opção a tomar é fruto de uma razão quase aritmética e que somente há um caminho possível, inadiável e imutável". Nesse contexto é que a questão do déficit fiscal tem sido reiteradamente utilizada como justificativa de reformas inadiáveis da previdência social. Outra argumentação recorrente é a acelerada alteração do perfil demográfico brasileiro, decorrente do aumento do número de pessoas idosas em razão da diminuição da taxa de natalidade e do aumento da 
expectativa de sobrevida da população. Com isso, mal termina uma Reforma, já se especula em quanto tempo virá a próxima, por ter sido a anterior insuficiente para conferir equilíbrio ao sistema. Contudo, é preciso lembrar que nem a seguridade nem a previdência são problemas eminentemente técnicos, que possam ser reduzidos a aspectos de natureza fiscal ou demográfica. $\mathrm{O}$ ambiente político está imbricado e condiciona o processo decisório acerca do modelo do sistema previdenciário.

O presente artigo tem por objetivo descrever e analisar a Reforma da Previdência Social empreendida pelo Congresso Nacional por iniciativa do Governo do Presidente Luiz Inácio Lula da Silva (2003/2006), de modo, inclusive, a aclarar os aspectos técnicos nela embutidos. Essa Reforma desdobrou-se em duas Emendas Constitucionais (EC). A primeira delas, a Emenda Constitucional $n^{\circ} 41$, de 19 de dezembro de 2003, foi fruto da iniciativa do Poder Executivo, que enviou a proposta ao Congresso Nacional logo no início do Governo, em 30 de abril de 2003. Após oito meses de tramitação, a proposição foi aprovada, guardando coerência, em linhas gerais, com a sugestão governamental.

Entretanto, o Governo e sua base de apoio parlamentar tiveram de construir, no Senado Federal, um acordo com a oposição, que resultou na iniciativa senatorial de uma nova proposta de emenda à Constituição, aprovada na Casa em conjunto com a anterior, e remetida à Câmara dos Deputados, contendo ajustes no texto encaminhado à promulgação e novas disposições. Após um ano e meio de tramitação, foi promulgada e publicada a Emenda Constitucional $\mathrm{n}^{\mathrm{o}}$ 47, de 5 de julho de 2005.

Tais Emendas Constitucionais aprofundaram as alterações promovidas pelo Congresso Nacional no Governo do Presidente Fernando Henrique Cardoso. Por isso, este artigo inicia por descrever as características da Emenda Constitucional $\mathrm{n}^{\circ} 20$, de 15 de dezembro de 1998, que serviu de antecedente para a Reforma empreendida no Governo Lula, com o objetivo de mostrar o contexto e as tendências que se apresentavam desde aquela época. Em seguida, são dedicadas seções separadas para analisar, com a especificidade necessária, os impactos das alterações promovidas, respectivamente, pelas Emendas Constitucionais $\mathrm{n}^{\mathrm{o}} 41$, de 2003, e $\mathrm{n}^{\mathrm{o}}$ 47, de 2005. Por fim, conclui-se com breves considerações finais, nas quais se procura desvelar os resultados da Reforma constitucional do sistema previdenciário brasileiro. 


\section{Antecedente: a emenda constitucional n. 20, de 1998}

A primeira providência, ao tratarmos do complexo sistema previdenciário brasileiro, é procurar compreender os regimes que o compõe. Para tanto, adotamos, com adaptações, as classificações de Modesto (2004, p. 22) e Barroso (2004, p. 52-3). O sistema previdenciário é constituído de dois subsistemas básicos: o público e o privado.

O subsistema público, de caráter institucional (não contratual), é subdivido em: $a$ ) Regime Geral de Previdência Social (RGPS), gerido pelo Instituto Nacional de Seguro Social (INSS) e aplicável à generalidade dos empregados privados e públicos, regidos pela Consolidação das Leis do Trabalho (CLT), e segurados voluntários; e b) os Regimes Próprios de Previdência Social (RPPS), organizados em cada um dos entes federados (União, estados, Distrito Federal e municípios), aplicáveis aos servidores públicos, titulares de cargo efetivo, e aos membros de poder. Ressalte-se que os militares têm um regime próprio de previdência. $\mathrm{O}$ subsistema privado, de natureza contratual, facultativa e complementar, é subdividido em previdência complementar aberta, administrada por bancos e sociedades seguradoras, e previdência complementar fechada, administrada por fundos de pensão.

A questão previdenciária ganhou maior importância a partir do Plano Real, quando sua dimensão tornou-se mais clara e seu equacionamento financeiro mais difícil, além da exigência de elevados superávits primários nas contas públicas (GUERZONI FILHO, 2004, p. 148). Logo no início de seu primeiro Governo, o Presidente Fernando Henrique Cardoso, em 28 de março de 1995, submeteu ao Congresso Nacional uma proposta de emenda à Constituição (PEC), com o objetivo de corrigir distorções do sistema previdenciário brasileiro, incidentes, sobretudo, após a edição da Constituição Federal de 1988. Embora já houvesse, na época, a discussão acerca da unificação dos regimes previdenciários dos servidores públicos e dos trabalhadores da iniciativa privada, o Governo optou, na proposta, por manter os regimes separados, mas sujeitos, na medida do possível, a regras uniformes (AMARO, 2004, p. 6).

Após longa tramitação, que durou quase uma legislatura (1.358 dias, entre $1995 \mathrm{e}$ 1998), foi promulgada a Emenda Constitucional $n^{\circ} 20$, de 16 de dezembro de 1998, que, embora diferente da proposta original, continha alterações significativas no sistema previdenciário, sobretudo em busca de um maior equilíbrio financeiro da previdência social. As alterações promovidas por essa Emenda foram exaustivamente discutidas em inúmeros trabalhos. Interessa-nos aqui, tão-somente, lembrar alguns aspectos relevantes, que servirão de base à análise das emendas constitucionais posteriores e seus efeitos. 
Assim, importa recordar que, tanto no RPPS quanto no RGPS, foi extinta a aposentadoria proporcional e substituída a aposentadoria por tempo de serviço pela aposentadoria por tempo de contribuição. Para o regime dos servidores públicos, foi imposta idade mínima para aposentadoria integral por tempo de contribuição, tanto na regra permanente quanto na transitória, o que possibilitou reduzir as despesas previdenciárias no médio e longo prazos, em vista do adiamento das aposentadorias. Contudo, o Congresso Nacional rejeitou a imposição de limites de idade nas regras da aposentadoria por tempo de contribuição pelo RGPS.

No RPPS, estabeleceu-se carência, para aposentadoria voluntária, de dez anos de efetivo exercício no serviço público e de cinco anos no cargo em que se daria a aposentadoria. O objetivo da medida foi garantir um fluxo mínimo de receita de contribuições, compatíveis com o benefício a ser auferido, impedindo que o servidor que tivesse trabalhado no setor privado e contribuído nos limites do RGPS ingressasse no serviço público e quase que imediatamente solicitasse a aposentadoria, graças à contagem recíproca de tempo de contribuição. Isso gerava grave distorção, pois o valor da aposentadoria ou pensão tomava por base a remuneração integral do servidor. Também ficaram vedadas: a percepção de mais de uma aposentadoria pelo RPPS, exceto no caso de cargos acumuláveis na forma da Constituição; e a contagem de qualquer forma de tempo de contribuição fictício.

A EC 20/98 viabilizou a reestruturação da previdência privada, de caráter complementar, prevendo a edição de leis complementares destinadas a tratar de regras gerais do sistema (art. 202, caput; Lei Complementar $\mathrm{n}^{\mathbf{0}}$ 109, de 2001) e de regras específicas do relacionamento entre empresas estatais e seus fundos de pensão (art. 202, § 4; Lei Complementar $n^{\circ} 108$, de 2001).

A Emenda facultou, ainda, a instituição de previdência complementar para os servidores públicos, com a possibilidade de criação de regimes de previdência complementar para a União, estados, Distrito Federal (DF) e municípios. Feito isso, os entes federados poderiam fixar o mesmo teto do RGPS para as aposentadorias e pensões a serem concedidas a seus servidores, cabendo ao servidor recorrer aos fundos instituídos para auferir renda adicional.

No RGPS, promoveu-se uma importante alteração, com a retirada da previsão constitucional da forma de cálculo dos benefícios (antigo art. 202), o que abriu caminho para substancial alteração por lei (Lei $\mathrm{n}^{\circ}$ 9.876, de 1999), mediante introdução do fator previdenciário, que permitiu considerar, na apuração do valor, fatores como a idade do 
beneficiário, a expectativa de vida e o tempo de contribuição. Isso conferiu maior equilíbrio atuarial e financeiro ao regime, embora com sacrifício do valor das aposentadorias e pensões.

\section{A emenda constitucional n. 4, de 2003}

Tal como ocorrido no governo anterior, o Presidente Luiz Inácio Lula da Silva não tardou a apresentar uma proposta de emenda à Constituição (PEC) com o intuito de reformar a previdência social. Em 30 de abril de 2003, a Câmara dos Deputados recebeu e deu início à tramitação da matéria (numerada como PEC no 40, de 2003). No dia 27 de agosto de 2003, menos de quatro meses após o início de sua tramitação, a matéria foi aprovada em segundo turno, demonstrando a força política que o Governo então detinha na Casa.

No Senado Federal, não foi muito diferente o tempo em que a proposta tramitou. Em 11 de dezembro de 2003, a matéria foi aprovada em segundo turno. Contudo, foram opostas maiores resistências às propostas do Governo. A aprovação da PEC ( $\left(n^{\circ} 67\right.$, de 2003, no Senado), somente foi obtida com a celeridade desejada pelo Executivo por meio de acordo com a oposição. Chegou-se a um texto de consenso, que resultou na Emenda Constitucional $\mathrm{n}^{\mathrm{o}} 41$, de 19 de dezembro de 2003, mas os pontos polêmicos passaram a constituir nova proposta de emenda à Constituição ( $\mathrm{n}^{\circ}$ 77, de 2003), apresentada por senadores e aprovada em seguida, no dia 17 de dezembro de 2003.

Neste sentido, é interessante observar a eficiência com que manobrou o Governo Lula. Enquanto no governo anterior a reforma previdenciária havia levado quase uma legislatura para ser aprovada, o Governo iniciado em 2003 levou apenas oito meses para ver sua proposta promulgada, embora alguns ajustes ainda fossem reconhecidamente necessários. É evidente que não se pode fazer uma leitura simplista desse dado, como depois vieram a demonstrar os fatos políticos. Entretanto, deve-se reconhecer que o tento do Governo Lula deveu-se, em boa medida, à reforma anterior, que já havido vencido as primeiras resistências e conseguido implementar alterações significativas no sistema previdenciário. A mídia impulsionou a proposta e potencializou o "rolo compressor" político do governo recém-eleito. A reforma teve amplo apoio dos governadores, pressionados pelas contas públicas, o que facilitou sua aprovação na Câmara dos Deputados (o Senado compunha-se de lideranças regionais, muitas vezes de oposição aos governos estaduais). Importante, ainda, considerar que os principais opositores à Reforma dos anos 1990 eram exatamente os patrocinadores da proposta e que os promotores da reforma anterior tinham dificuldade de fazer oposição à nova Reforma, que guardava consonância com a que eles haviam promovido. 
Outro aspecto relevante foi o fato de que a Reforma proposta tinha escopo bem mais limitado do que a anterior, pois se restringia ao regime dos servidores públicos e membros de poder. As mudanças eram pequenas no RGPS e, no regime de previdência complementar, a intenção era superar a paralisia no andamento do Projeto de Lei Complementar (PLP no 9, de 1999). A Reforma também não alterava diretamente o regime dos militares, preferindo remeter sua disciplina para a legislação infraconstitucional.

Vale lembrar, ainda, que a reforma previdenciária constava dos compromissos da vitoriosa campanha para a Presidência. A necessidade da Reforma constava no Programa de Governo do Partido dos Trabalhadores (PT) na campanha presidencial de 2002. Nela, já se delineiam os argumentos posteriormente utilizados para colocar a Reforma Previdenciária novamente na agenda de deliberações do Congresso Nacional: o desequilíbrio financeiro da previdência, o redirecionamento dos recursos para políticas sociais, os aspectos demográficos, e a busca por eqüidade e justiça mediante unificação dos sistemas previdenciários dos celetistas e dos servidores públicos.

A Exposição de Motivos Interministerial (EMI) no 29-MPS/CCIVIL-PR, de 29 de abril de 2003, encaminhada pelos Ministros de Estado da Previdência Social, Ricardo Berzoini, e da Casa Civil, José Dirceu, que acompanha a remessa da proposta de emenda à Constituição ao Congresso Nacional, inicia com a lembrança de que, no Programa de Governo, a reforma do sistema previdenciário ganhava destaque como um dos instrumentos de um "novo modelo de desenvolvimento, que englobe crescimento, emprego e eqüidade social". Para tanto, buscava-se a construção, no longo prazo, de um "regime previdenciário básico público, universal, compulsório, para todos os brasileiros" (BRASIL, 2003).

Contudo, argumenta que a reforma anterior teve abrangência incompleta e parcial. Embora tenha modificado princípios da administração previdenciária do setor público, em especial o caráter contributivo e o equilíbrio financeiro-atuarial, deixou persistir regras bastante diferenciadas entre o regime geral de previdência social e os regimes próprios dos servidores públicos, com "desequilíbrios nas dimensões de eqüidade e sustentabilidade de longo prazo". O que se buscava era a convergência de regras, para tornar a previdência social mais equânime, socialmente mais justa e viável financeira e atuarialmente a longo prazo.

Como bem lembra Amaro (2004, p. 14), o diagnóstico do Governo Lula era o de que ainda havia o que aprimorar, principalmente no RPPS, porque sua necessidade de financiamento (diferença entre as despesas com inativos e pensionistas e as receitas de contribuição) no ano de 2002, consideradas as três esferas de governo, girou em torno de 39,1 
bilhões de reais, o que correspondia a $3 \%$ do PIB brasileiro, o que pressionava significativamente as contas públicas e comprometia o ajuste fiscal do Estado.

Entretanto, Guerzoni Filho (2004, p. 151-159) demonstra que a EC 20/98 permitiu que os dispêndios com aposentados e pensionistas civis da União apresentassem crescimento abaixo da inflação. No período 1995-2003, as despesas cresceram 104,6\%, enquanto a variação do IPCA foi de 119,3\%. Verificou-se redução, ainda, na comparação entre as despesas com inativos e pensionistas do serviço público civil com a receita corrente total da União, que era de $8 \%$ em 1995, e passou a pouco mais de 3\% em 2003. Também em relação à distribuição das despesas da União, os dispêndios com a previdência dos servidores civis representavam cerca de 7\% em 1995 e passaram a 4\% em 2003. A situação é outra se analisadas as previdências dos militares e do RGPS, no mesmo período. Em ambos os casos, as despesas subiram acima da inflação e as despesas em função da receita corrente total permaneceram praticamente estáveis. $\mathrm{Na}$ distribuição com as despesas da União, os gastos com a previdência militar diminuíram de $3 \%$ para $2 \%$, mas a situação do RGPS mostrou tendência preocupante, elevando-se de $20 \%$ para $22 \%$. Contudo, a Reforma Previdenciária no Governo Lula centrou-se, quase que exclusivamente, nos servidores públicos. Para o autor, o móvel da proposta foi mais demonstrar a capacidade de "fazer mudança em matéria importante", do que propriamente equacionar a questão previdenciária, visto que, após a EC 20/98, já tinha havido uma significativa melhora no quadro das despesas referentes à previdência dos servidores públicos civis.

Mas os servidores públicos civis foram o grande alvo da Reforma, conforme intenção claramente exposta por Berzoini (2003, p. 20), na época Ministro de Estado da Previdência Social:

Cada real que falta para o pagamento de aposentadorias e pensões no Brasil é coberto com tributos arrecadados de toda a população, pagos inclusive pela parcela mais pobre. Em 2002, a arrecadação tributária do setor público destinou 56 bilhões ao pagamento desses benefícios nos dois sistemas previdenciários existentes. O regime do INSS precisou de R $\$ 17$ bilhões para fechar suas contas e cumprir seus compromissos com 19 milhões de beneficiários. O sistema do setor público precisou de $\mathrm{R} \$ 39$ bilhões, mais que o dobro, para pagar benefícios a 3,2 milhões de pessoas, menos que um quinto. Foram R \$ 894 para cada beneficiário do INSS e R \$ 12.187 para cada beneficiário dos regimes dos servidores. Reduzir essa desigualdade e a pressão sobre os Orçamentos da União, dos Estados, do Distrito Federal e dos Municípios significa liberar esses recursos orçamentários para outras finalidades, como moradia, saneamento, educação, saúde e segurança, além de melhor política de remuneração dos servidores públicos e o aumento do salário mínimo. 
A partir daí retoma-se o discurso dos privilégios dos servidores públicos, que procura caracterizá-los como únicos responsáveis pelo déficit de todo o sistema, com ampla repercussão na mídia. As críticas deliberadamente centram-se em uma característica que o sistema jamais adotou, qual seja, a vinculação entre contribuições e benefícios, típica dos regimes de capitalização (mas não dos regimes de repartição, como é o caso).

Mas não deixou de ser utilizada, também com ênfase nos privilégios dos servidores públicos, a argumentação da acelerada alteração do perfil demográfico brasileiro, decorrente do aumento do número de pessoas idosas em razão da diminuição da taxa de natalidade e do aumento da expectativa de sobrevida da população. Segundo a Exposição de Motivos, entre 1991 e 2000 houve um crescimento de 35,6\% na quantidade total de pessoas idosas (60 anos ou mais) no país. Os idosos, que compunham 7,3\% da população passaram, no período, a representar $8,6 \%$, sendo o segmento que mais cresceu. Houve, ainda, melhora na expectativa de sobrevida. Um homem de 50 anos tinha, em 2001, uma expectativa de sobrevida de mais 23,4 anos, isto é, deverá chegar aos 73,4 anos. Alega-se, então, que o envelhecimento da população sobrecarrega os regimes de previdência, sobretudo o dos servidores públicos, para os quais tradicionalmente eram oferecidas aposentadorias em idades precoces. Por tal razão, a Reforma deveria desestimular as aposentadorias, mediante redução dos valores dos benefícios, e incentivar a permanência do servidor na atividade, por meio de abono. No regime geral, entende-se dispensável a fixação de idade mínima, pois os trabalhadores da iniciativa privada, especialmente os de baixa renda, oscilam entre a formalidade e a informalidade, geralmente tendo acesso à aposentadoria somente por idade, com 65 anos, se homem, ou 60, se mulher.

Em síntese, a Reforma teve como objetivos declarados: a correção das distorções do modelo, propiciando eqüidade entre os regimes; a flexibilização da política de recursos humanos; a adequação ao perfil demográfico brasileiro; a melhoria dos resultados fiscais; e a garantia de que as obrigações decorrentes das previsões constitucionais seriam cumpridas em relação ao direito do servidor público aposentar-se "sem privar o restante da sociedade dos recursos necessários para o crescimento e desenvolvimento desta Nação".

\section{O fim da integralidade e paridade nas regras permanentes}

Uma das mais relevantes alterações da EC 41/03 foi o fim da integralidade como regra permanente do RPPS. Com efeito, até então, os proventos de aposentadoria eram calculados com base na remuneração do servidor no cargo efetivo em que se dava a 
aposentadoria e, na forma da lei, correspondiam à totalidade da remuneração. Essa regra fugia à sistemática de qualquer modelo previdenciário, pois não havia relação entre as contribuições efetivadas e os benefícios concedidos. Tal fato era agravado pela possibilidade de o servidor ser egresso da iniciativa privada, caso em que teria contribuído durante muitos anos nos limites do RGPS. A EC 20/98 exigiu a carência de pelo menos dez anos de serviço público, mas mesmo assim o problema persistia. A nova regra do $\S 3^{\circ}$ do art. 40 altera essa sistemática, ao dispor que para o cálculo dos proventos de aposentadoria, por ocasião de sua concessão, são consideradas as remunerações utilizadas como base para as contribuições do servidor aos regimes de previdência, próprio (RPPS) e geral (RGPS), na forma da lei.

Mas não foi só. A EC 41/03 também conseguiu romper, no texto permanente, a chamada paridade, isto é, a equivalência obrigatória entre os reajustes dos proventos de aposentadoria e das pensões e os das remunerações dos servidores ativos. Essa regra, introduzida pela Constituição de 1988, garantia a revisão dos proventos de aposentadoria, na mesma proporção e na mesma data, sempre que se modificasse a remuneração dos servidores em atividade, ou a extensão aos inativos dos mesmos benefícios ou vantagens concedidos aos ativos, inclusive quando decorrente de transformação ou reclassificação de cargos ou função em que se deu a aposentadoria, na forma da lei (então $\S 4^{\circ}$ do art. 40). A EC 20/98 manteve a disposição, apenas dando novo número ao parágrafo ( $\S 8^{\circ}$ do art. 40). Essa regra não se assentava em lógica previdenciária e causava embaraços à administração de recursos humanos do setor público, pois as alterações em planos de carreira tinham imediata correspondência nos inativos.

Com a EC 41/03, contudo, os servidores passam a contar apenas com a garantia da preservação do valor real dos seus proventos, conforme critérios estabelecidos em lei (nova redação do $\S 8^{\circ}$ do art. 40). Evidente que isso traz o risco de se repetir situações do passado, quando ocorria a gradual deterioração do valor dos proventos e pensões, cuja reposição em termos "reais" fica dependente dos critérios adotados pela lei e das disponibilidades orçamentárias e financeiras dos entes públicos. Contudo, é de se perceber que o fim da integralidade e da paridade conduz à aproximação entre as regras do RPPS e do RGPS, na medida em que os benefícios são calculados em função das contribuições do servidor.

Valor das pensões por morte

Antes, a pensão por morte correspondia ao valor dos proventos do servidor falecido ou ao valor dos proventos a que teria direito o servidor em atividade na data de seu 
falecimento. A EC 41/03 alterou a sistemática de cálculo, determinando que a lei disponha sobre a concessão do benefício, que deverá ser igual:

a) para o aposentado na data do óbito, ao valor da totalidade dos proventos do servidor falecido, até o limite máximo estabelecido para os benefícios do RGPS, acrescido de setenta por cento da parcela excedente a este limite; ou

b) caso o servidor estivesse em atividade na data do óbito, ao valor da totalidade da remuneração do servidor no cargo efetivo em que se deu o falecimento, até o limite máximo estabelecido para os benefícios do RGPS, acrescido de setenta por cento da parcela excedente a este limite.

A alteração fundamentou-se no argumento de que a perda de um membro da família implica a necessidade de uma renda menor. Contudo, embora haja previsão de que a lei disporá sobre o benefício, o texto constitucional já deixa consignado que, após o teto do RGPS, o benefício corresponderá a setenta por cento do excedente, ou seja, já antecipou o percentual, sem aferição do impacto da redução (por exemplo, pelo número de dependentes). Além disso, há diferença entre a pensão decorrente da morte do aposentado ou do servidor em atividade. Enquanto no caso do servidor anteriormente ativo a pensão deve corresponder a setenta por cento do excedente, ou seja, do teto do RGPS até a remuneração integral, no caso do aposentado falecido esse excedente deve se dar sobre os proventos de aposentadoria, que não são mais integrais.

Importante observar que o critério da redução da renda familiar com o falecimento aplica-se no que ultrapassar o limite do RGPS. Tal redução, por decorrência, não teve correspondente no RGPS. A redução não se aplica, ainda, para a pensão do servidor público se o valor não superar o teto dos benefícios do RGPS. Com isso, pode-se concluir que o propósito verdadeiro do dispositivo é a aproximação das regras dos regimes.

\section{As regras de transição}

As regras de transição da EC 41/03, dentro do espírito de reforma do RPPS pelo Governo Lula, são extremamente severas, sobretudo se comparadas com a da EC 20/98. São duas as opções de transição.

A primeira opção é destinada aos servidores que tenham ingressado em cargo efetivo da Administração Pública até a publicação da EC 20/98, ou seja, é uma alteração da regra de transição prevista na EC 20/98, comandada pelo art. $2^{\circ}$ da EC 41/03. De início, observa-se que a aposentadoria proporcional, antes suprimida da regra permanente, foi agora 
extinta na transição. A opção tem por requisitos cumulativos que o servidor: a) tenha cinqüenta e três anos de idade, se homem, e quarenta e oito anos de idade, se mulher; b) tenha cinco anos de efetivo exercício no cargo em que se der a aposentadoria; e c) conte tempo de contribuição igual, no mínimo, à soma de trinta e cinco anos, se homem, e trinta anos, se mulher, e um período adicional de contribuição equivalente a vinte por cento do tempo que faltaria para atingir o referido tempo de contribuição.

Atendidas essas condições, o servidor pode aposentar-se, mas não faz jus à integralidade, ou seja, sua remuneração é calculada por fórmula que leva em consideração as contribuições efetuadas para os dois regimes, RPPS e RGPS, atualizadas monetariamente (art. $40, \S \S 3$ e 17). Mas o valor não se limita ao teto do RGPS. Entretanto, a correção se dará pela nova regra de preservação do valor real, sem paridade.

O servidor terá os seus proventos de inatividade reduzidos para cada ano antecipado em relação à idade de sessenta anos, se homem, e cinqüenta e cinco anos, se mulher, na seguinte proporção: a) três inteiros e cinco décimos por cento, para aquele que completar as exigências até 31 de dezembro de 2005 ; b) cinco por cento, para aquele que completar as exigências a partir de $1^{\circ}$ de janeiro de 2006. Como os limites mínimos de idade, na transição, estão distantes sete anos da idade da regra permanente, a redução poderá chegar, no último caso, a trinta e cinco por cento.

Essa opção de transição se aplica aos magistrados, membros do Ministério Público e do Tribunal de Contas, mas, se homem, o tempo de serviço exercido até a data de publicação da EC 20/98 é contado com acréscimo de dezessete por cento. A opção também beneficia, desde que se aposente exclusivamente com tempo de efetivo exercício nas funções de magistério, o professor, servidor da União, dos estados, do Distrito Federal e dos municípios, incluídas suas autarquias e fundações, que, até a data de publicação da EC 20/98 tenha ingressado, regularmente, em cargo efetivo de magistério, caso em que terá o tempo de serviço exercido até a publicação da EC 20/98 contado com o acréscimo de dezessete por cento, se homem, e de vinte por cento, se mulher.

A segunda opção destina-se aos servidores da União, dos estados, do Distrito Federal e dos municípios, incluídas suas autarquias e fundações, que tenha ingressado no serviço público até a data de publicação da EC 41/03, ressalvado o direito de utilizarem a regra permanente ou a opção anterior, se possível (art. $6^{\circ}$ da EC 41/03). As condições cumulativas para o servidor se aposentar, nesta opção, são as seguintes: a) sessenta anos de idade, se homem, e cinqüenta e cinco anos de idade, se mulher; b) trinta e cinco anos de contribuição, se homem, e trinta anos de contribuição, se mulher; c) vinte anos de efetivo 
exercício no serviço público; e d) dez anos de carreira e cinco anos de efetivo exercício no cargo em que se der a aposentadoria. Incidem aqui as reduções de idade e tempo de contribuição, em cinco anos, para o professor que comprove exclusivamente tempo de efetivo exercício das funções de magistério na educação infantil e no ensino fundamental e médio.

Nesta opção, o servidor garante, na aposentadoria, a integralidade, ou seja, aposenta-se com proventos integrais, que correspondem à totalidade da remuneração no cargo efetivo em que se der a aposentadoria, na forma da lei. Os proventos serão revistos na mesma proporção e na mesma data, sempre que se modificar a remuneração dos servidores em atividade, na forma da lei (parágrafo único do art. $6^{\circ}$ da EC 41/03). O reajuste fica, portanto, dependendo de legislação ulterior, não incidindo imediatamente nem a paridade nem a preservação do valor real.

Pelas árduas condições estabelecidas, verifica-se que a EC 41/03 atingiu duramente as expectativas dos servidores públicos ainda em contagem de tempo para exercício do direito à aposentadoria.

\section{Abono de permanência}

Caso o servidor complete os requisitos da aposentadoria voluntária prevista no art. $40, \S 1^{\circ}$, III, $a$, quais sejam, sessenta anos de idade e trinta e cinco de contribuição, se homem, e cinqüenta e cinco anos de idade e trinta de contribuição, se mulher, e opte por permanecer em atividade, fará jus a um abono de permanência equivalente ao valor de sua contribuição previdenciária (art. 40, § 19). Na prática, o servidor tem um incremento em sua remuneração líquida correspondente ao que antes recolhia como contribuição. Esse benefício poderá ser usufruído até que se dê a aposentadoria compulsória, aos setenta anos de idade (art. $40, \S 1^{\circ}$, II).

\section{Contribuições dos inativos e pensionistas}

O ponto de maior polêmica na EC 41/03 foi, sem dúvida, o que dizia respeito à contribuição dos inativos e pensionistas. O Supremo Tribunal Federal já repelira a tentativa de instituí-la por meio de lei, no julgamento da Medida Cautelar na Ação Direta de Inconstitucionalidade $\mathrm{n}^{\mathrm{o}}$ 2.010, que contestava dispositivos da Lei $\mathrm{n}^{\mathrm{o}}$ 9.783, de 1999 (BRASIL, Supremo Tribunal Federal, 1999). O Governo Lula, porém, decidiu e conseguiu empreender a alteração na Constituição Federal necessária para viabilizar a pretendida 
contribuição sobre as aposentadorias e pensões do RPPS que superem o valor máximo de benefício do RGPS, com percentual igual ao estabelecido para os titulares de cargos efetivos (art. 40, § 18).

Mas também aqui foi mais longe a EC 41/03, ao fazer alcançar os inativos e pensionistas em gozo de benefícios na data de publicação da Emenda, assim como os que já haviam cumprido, até então, os requisitos para obtenção de aposentadoria e pensão, cuja contribuição passariam a se dar nos mesmos percentuais estabelecidos para os servidores efetivos ativos. Contudo, com o argumento de que aqueles teriam contribuído menos para a previdência, aprovou-se uma faixa menor de isenção para a contribuição do que a dos servidores ativos (art. $4^{\mathrm{o}}$, caput). Conforme art. $4^{\mathrm{o}}$, parágrafo único, da EC 41/03, a contribuição previdenciária incide apenas sobre a parcela dos proventos e das pensões que supere: a) cinqüenta por cento do limite máximo estabelecido para os benefícios do RGPS, para os servidores inativos e os pensionistas dos estados, do Distrito Federal e dos municípios (inciso I); b) sessenta por cento do limite máximo estabelecido para os benefícios do RGPS, para os servidores inativos e os pensionistas da União (inciso II).

Levada, como esperado, a questão ao Poder Judiciário, por intermédio da Ação Direta de Inconstitucionalidade $\mathrm{n}^{\mathrm{o}} 3.105$ e outras, o Supremo Tribunal Federal decidiu, por maioria, pela constitucionalidade da contribuição dos inativos, sob fundamento de que não há norma jurídica que imunize os proventos e as pensões, de modo absoluto, à tributação de ordem constitucional, qualquer que seja a modalidade do tributo, além da invocação aos princípios da solidariedade e do equilíbrio financeiro e atuarial, bem como aos objetivos constitucionais de universalidade, eqüidade na forma de participação no custeio e diversidade da base de financiamento da previdência social (BRASIL, Supremo Tribunal Federal, 2004b).

Contudo, a Corte entendeu que as bases de cálculo diferenciadas, estabelecidas nos incisos do parágrafo único do art. $4^{\circ}$, implicaram tratamento discriminatório entre servidores e pensionistas da União, de um lado, e servidores e pensionistas dos estados, do Distrito Federal e dos municípios, de outro. Com isso, deu-se ofensa ao princípio constitucional da isonomia tributária, que é particularização do princípio fundamental da igualdade. Desse modo, declarou inconstitucionais as expressões "cinqüenta por cento do" e "sessenta por cento do", constantes nos dispositivos referidos. Em conseqüência, foi reestabelecido o caráter geral da regra do art. 40, § 18, com a redação da EC 41/03, ou seja, todas as contribuições devem incidir sobre o valor que supere o limite máximo de benefício do RGPS, com percentual igual ao estabelecido para os titulares de cargos efetivos. 
Ultrapassada a questão constitucional, vale observar alguns importantes efeitos da instituição da contribuição previdenciária dos inativos e pensionistas, sob o ponto de vista do mérito. Essa contribuição significa um aporte de recursos para o financiamento do regime previdenciário dos servidores públicos. Esses valores, contudo, tendem a não serem tão significativos, em face da isenção até o limite do RGPS. Mas há também o aspecto de eqüidade. Se no RGPS não há contribuição sobre aposentadorias e pensões (art. 195, II), também no RPPS não há contribuição se o provento de aposentadoria não ultrapassar o limite do regime geral. A contribuição somente incidirá sobre a parcela que supere o teto do benefício no RGPS, ou seja, naquilo que o regime dos servidores apresenta de vantagem em relação aos segurados em geral.

\section{Teto de remuneração para os servidores públicos}

O tema não é estritamente matéria previdenciária, mas tem repercussão na previdência, por meio da fixação da remuneração dos servidores e membros de Poder. Assim, foi objeto das Emendas Constitucionais $n^{\circ} 19$ (Reforma Administrativa) e 20 (Reforma Previdenciária), ambas de 1998. Contudo, as deliberações ali tomadas não chegaram a ser efetivadas, por falta da norma infraconstitucional necessária. É que a EC 19/98 fixou que a remuneração e o subsídio dos ocupantes de cargos, funções e empregos públicos da administração direta, autárquica e fundacional, dos membros de qualquer dos Poderes da União, dos estados, do Distrito Federal e dos municípios, dos detentores de mandato eletivo e dos demais agentes políticos e os proventos, pensões ou outra espécie remuneratória, percebidos cumulativamente ou não, incluídas as vantagens pessoais ou de qualquer outra natureza, não poderiam exceder o subsídio mensal, em espécie, dos Ministros do Supremo Tribunal Federal (art. 37, § 11).

Contudo, a fixação do subsídio dos Ministros do Supremo Tribunal Federal, parâmetro de aplicação da norma, deveria se dar por lei de iniciativa conjunta dos presidentes da República, da Câmara dos Deputados, do Senado Federal e do Supremo Tribunal Federal (art. 48, XV), o que nunca ocorreu. Ficou, portanto, inviabilizada a aplicação prática do teto, até a edição da EC 41/03, que alterou alguns parâmetros de aplicação para sua aplicação, previu que a lei de fixação do subsídio dos Ministros do STF seria de iniciativa apenas do Poder Judiciário, e deu regulamentação transitória ao assunto em seu art. $8^{\circ}$. De qualquer modo, em 26 de julho de 2005, foi publicada a Lei $\mathrm{n}^{\circ} 11.143$, que fixou o referido subsídio. 
Quanto aos parâmetros de aplicação do teto, observa-se que não há mais um único teto para todos os entes federados, como dispunha a EC 20/98. O teto passa a ter limites específicos, conforme a esfera federativa, aplicando-se: a) nos municípios, o subsídio do prefeito; b) e nos estados e no Distrito Federal, o subsídio mensal do governador no âmbito do Poder Executivo, o subsídio dos deputados estaduais e distritais no âmbito do Poder Legislativo e o subsídio dos desembargadores do Tribunal de Justiça, limitado a noventa inteiros e vinte e cinco centésimos por cento do subsídio mensal, em espécie, dos Ministros do Supremo Tribunal Federal, no âmbito do Poder Judiciário, aplicável este limite aos membros do Ministério Público, aos procuradores e aos defensores Públicos; c) na União, o subsídio mensal dos Ministros do Supremo Tribunal Federal.

Quanto à composição, o art. 37, XI, da Constituição, com a redação dada pela EC 41/03, determina que o teto contempla a remuneração e o subsídio dos ocupantes de cargos, funções e empregos públicos da administração direta, autárquica e fundacional, dos membros de qualquer dos poderes da União, dos estados, do Distrito Federal e dos municípios, dos detentores de mandato eletivo e dos demais agentes políticos e os proventos, pensões ou outra espécie remuneratória, percebidos cumulativamente ou não, incluídas as vantagens pessoais ou de qualquer outra natureza. As duas expressões destacadas merecem comentários. Pela primeira, aplica-se o teto à soma da remuneração, subsídio, proventos ou pensões recebidas pelo servidor ou membro de Poder, e não a cada uma delas separadamente. Desse modo, mesmo que haja acumulação legal, na atividade ou na inatividade, o teto incidirá simultaneamente. Quanto à segunda expressão, a inclusão das vantagens pessoais confere maior efetividade à norma, já que anteriormente a jurisprudência não vinha admitindo a inclusão das vantagens pessoais no teto.

Entretanto, o Supremo Tribunal Federal entendeu que esse dispositivo deve sofrer temperamento, conforme sessão administrativa na qual se tratou da aplicação interna do art. $8^{\circ}$ da EC 41/03 (maior remuneração atribuída por lei a ministro do STF, a ser considerada como teto). Em nota divulgada à imprensa, em 5 de fevereiro de 2004, o Tribunal indicou que deverão se excluídas do teto simultâneo as acumulações que tenham guarida na própria Constituição Federal:

[...] 2-O Supremo Tribunal Federal entendeu que os valores recebidos pelos ministros do Tribunal Superior Eleitoral a título de gratificação de presença, na forma da Lei 8.350/91, não integram o cálculo do limite fixado pelo citado artigo $8^{\circ}$ da Emenda 41/2003. Por outro lado, esses valores não podem se somar à remuneração dos ministros do Supremo para fins de repercussão prática do teto. É que, se assim não se entendesse, haveria norma constitucional sem eficácia, exatamente aquela que determina que o TSE 
seja composto por ministros do STF (CF, artigo 119). Se esses já recebem o teto no Supremo, estariam impedidos de receber a remuneração pelo trabalho no TSE e, conseqüentemente, de compor a corte eleitoral. 3- Não se admite que normas constitucionais de igual hierarquia sejam antagônicas, de forma que uma anule a outra. Nessas situações, é preciso que haja uma conformação das regras constitucionais. Assim, no caso específico do TSE, o artigo 119 da Constituição e o artigo $8^{\circ}$ da emenda constitucional 41/03 interpretam-se harmonicamente. [...]. (BRASIL, Supremo Tribunal Federal, 2004a).

Por sua vez, o art. $9^{\circ}$ da EC 41/03 comanda a aplicação imediata do art. 17 do Ato das Disposições Constitucionais Transitórias (ADCT), segundo o qual o teto tem aplicação para os vencimentos, a remuneração, as vantagens e os adicionais, bem como os proventos de aposentadoria que estejam sendo percebidos em desacordo com esse limite, não se admitindo invocação de direito adquirido ou percepção de excesso a qualquer título.

O Supremo Tribunal Federal, no julgamento do Mandado de Segurança (MS) $n^{\circ}$ 24.875, em que ministros aposentados da própria Corte contestavam a redução de seus proventos pela aplicação da nova redação do art. 37, XI, e do art. $8^{\circ}$ da EC 41/03, em sessão plenária de 9 de março de 2006, decidiu, por unanimidade, que os adicionais por tempo de serviço devem ser incluídos no teto e que nenhuma vantagem pessoal poderá ser paga além do limite remuneratório. Contudo, na continuidade da sessão, em 11 de maio de 2006, o STF, por maioria, assegurou a manutenção de vantagem conferida à época da passagem dos impetrantes para a aposentadoria, pois concedida com base na lei vigente è época e em harmonia com a interpretação do STF. Ressalvou, porém, que não se tratava de admitir direito adquirido a determinado regime jurídico, modificado por legislação superveniente, mas sim de respeito à garantia da irredutibilidade de vencimentos. Tal garantia assegura a percepção do montante global dos vencimentos ou proventos, e não a manutenção de percentuais que integram o seu cálculo, de modo que a vantagem somente será recebida até que seu montante seja coberto pelo subsídio fixado em lei para os Ministros do Supremo Tribunal Federal (BRASIL, Supremo Tribunal Federal, 2006).

\section{Previdência complementar dos servidores públicos}

A EC 20/98 havia previsto a elaboração de leis complementares para regular o regime de previdência complementar dos servidores públicos. Duas delas foram editadas, mas uma outra, que disporia sobre normas gerais para instituição desse regime pela União, estados, Distrito Federal e municípios, para atender aos seus respectivos servidores, nunca chegou a ter sua votação concluída na Câmara dos Deputados. 
Os entraves na votação do Projeto de Lei Complementar (PLP) n 9, de 1999, estão na origem das modificações empreendidas pela EC 41/03. Isso porque a oposição ao projeto era conduzida pelos vencedores da eleição de 2002, que agora se viam, como Governo, na posição de ter de aprovar o projeto que combatiam. A polêmica estava em que o projeto dispunha que os planos de benefício seriam da modalidade de contribuição definida, na qual são fixadas as contribuições dos segurados, enquanto o valor do benefício é apurado a partir dessas contribuições e de sua rentabilidade.

A solução adotada, então, foi levar o tema para a Constituição Federal. Retirou-se do texto constitucional a previsão da lei complementar, e se dispôs que o regime de previdência complementar será instituído por lei de iniciativa do respectivo Poder Executivo, por intermédio de entidades fechadas de previdência complementar, de natureza pública, que oferecerão aos participantes planos de benefícios somente na modalidade de contribuição definida (§ 15 do art. 40).

$\mathrm{O}$ antagonismo entre previdência pública e previdência privada esteve sempre presente nas Reformas Previdenciárias. Os países do capitalismo central praticam combinações entre os sistemas públicos e privados. Na América Latina, entretanto, ganhou força a idéia de que a previdência privada é superior à previdência pública e deve, portanto, substituí-la. Contudo, a EC 20/98 abriu caminho para implantação de um modelo misto, que mantém uma previdência pública básica e cede espaço para uma previdência privada complementar. A EC 41/03 aprofundou essa inclinação, ao aproximar os regimes previdenciários, dos servidores públicos e dos trabalhadores em geral, em torno de um limite de benefício, a partir do qual deve-se buscar a previdência privada.

A previdência pública, tanto no regime geral quanto nos dos servidores públicos, adota o regime de repartição simples, no qual não há formação de uma poupança individual ou coletiva, pois os recursos apurados são transferidos para o pagamento dos atuais benefícios. O regime funciona como uma complexa cadeia de financiamento, que enlaça gerações diferentes, segundo o princípio da solidariedade intergeracional, ou seja, mediante transferência de renda entre gerações. Assim, o servidor ou o empregado não contribuem para a própria aposentadoria ou correspondente pensão, mas para a solvabilidade do sistema previdenciário respectivo (MODESTO, 2004, p. 27).

Já a previdência privada, de caráter contratual e filiação facultativa, funciona mediante regime de capitalização, na qual a formação de reservas se dá individualmente. Desse modo, a contribuição do segurado financia os próprios benefícios do segurado, sem solidariedade intergeracional. O valor da contribuição determina o valor do benefício futuro 
dos próprios agentes ou o tempo de contribuição, numa equação estritamente financeira (MODESTO, 2004, p. 29).

O regime privado brasileiro conhece duas variantes bastante distintas de previdência complementar: as entidades abertas e as entidades fechadas. As entidades abertas são sempre constituídas na forma de sociedades anônimas e atuam na oferta de planos individuais ou coletivos de previdência complementar, com fins lucrativos. Tais planos são acessíveis a qualquer um que os subscreva e custeie, podendo oferecer planos de benefício definido, de contribuição definida, de contribuição variável ou outra forma admitida pelo órgão regulador (Lei Complementar $n^{0} 109$, de 2001).

Diferentemente, os planos de previdência organizados por entidades fechadas são específicos dos empregados de determinada empresa ou grupo de empresas. Até a EC 41/03, eram constituídas sob a forma de fundação de direito privado ou sociedade civil sem fins lucrativos. Contudo, esta Emenda deu nova redação ao $\S 15$ do art. 40 da Constituição, dispondo que essas entidades terão natureza pública e somente poderão oferecer planos de contribuição definida. A natureza pública das entidades fechadas de previdência complementar, porém, não se afigura adequada. Essas entidades compõem a previdência privada complementar, não fazendo sentido que atendam a regime jurídico público. Tais entidades são tipicamente privadas, sobretudo porque seu patrimônio pertence a seus filiados e não ao tesouro público. Além disso, devem ter a flexibilidade de atuação típica do mercado privado, não fazendo sentido que estejam restritas a rígidas normas do direito público. Isso poderá comprometer a implantação e o funcionamento dessas entidades, ou mesmo inviabilizar a aplicação da norma constitucional. Adicionalmente, adverte Pinheiro (2003, p. 52), se adotada a natureza pública, as entidades poderão ficar vulneráveis a ingerências políticas, em razão da maior dificuldade de insulamento institucional, além do fato de que o Governo Federal encontrará maiores dificuldades para supervisionar e regular as entidades criadas por estados e municípios, devido à autonomia federativa.

\section{RGPS: teto de benefícios e inclusão previdenciária}

O foco principal da EC 41/03 foi o regime dos servidores públicos. Duas mudanças, contudo, atingiram o Regime Geral de Previdência Social (RGPS). A primeira foi a elevação do limite do salário-de-contribuição e do salário-de-benefício, de R \$ 1.561,56 para R\$ 2.400,00, equivalentes, na época, a dez salários mínimos. Deveria, a partir daí, ser reajustado de forma a preservar, em caráter permanente, seu valor real, atualizado pelos 
mesmos índices aplicados aos benefícios do RGPS (art. $5^{\circ}$ da EC 41/03). Essa alteração torna o regime mais adequado ao perfil de renda da iniciativa privada, em que a grande maioria dos salários são menores do que o limite estipulado. Entretanto, tem efeito a curto prazo somente na arrecadação, com o aumento do limite da última faixa na tabela de contribuições. Os efeitos sobre os benefícios serão diferidos no tempo, incidindo gradativamente na média das novas aposentadorias.

A segunda alteração no RGPS é a previsão de uma lei destinada a instituir um sistema especial de inclusão previdenciária para trabalhadores de baixa renda, garantindo-lhes acesso a benefícios no valor de um salário-mínimo, exceto aposentadoria por tempo de contribuição (§ 12 do art. 201). Essa norma sofreu ajuste na EC 47/05.

A emenda constitucional $n .47$, de 2005

Esta Emenda resultou da chamada "PEC Paralela da Previdência", que teve origem no Senado Federal (Proposta de Emenda à Constituição no 77, de 2003; n 227, de 2004, na Câmara dos Deputados). Seu objetivo foi viabilizar politicamente a aprovação da PEC n⿳ 67, de 2003 (EC 41/03), mantendo o texto oriundo da Câmara dos Deputados, que, por sua vez, seguia a linha da proposta formulada pelo Governo Lula.

Para compreender o contexto em que nasceu a "PEC Paralela", é preciso lembrar que as propostas de emenda à Constituição são discutidas e votadas em cada Casa do Congresso Nacional, em dois turnos, considerando-se aprovada se obtiver, em ambos, três quintos dos votos dos respectivos membros (art. 60, $\S 2^{\circ}$ ). Diferentemente do que ocorre com os projetos de lei que, se alterados pela Casa revisora, voltam para deliberação definitiva e preponderante da Casa iniciadora (art. 65), uma proposta de emenda constitucional somente é considerada aprovada se o mesmo texto for submetido à dupla deliberação em cada Casa. Isso obriga a que uma PEC, se alterada por uma Casa, seja necessariamente remetida à outra, para outra dupla deliberação sobre o texto. Essa sistemática pode ocorrer indefinidamente. Para evitá-la, passou a ser admitida a possibilidade de "fatiamento" do texto, de modo que a parte já aprovada em dois turnos nas duas Casas seja promulgada de imediato como emenda constitucional. Então, somente a parte alterada volta para a outra Casa.

Essa foi a estratégia utilizada. Após acalorados debates e negociações, a PEC 67/03 foi aprovada pelo Senado Federal, tendo-se transformado na EC 41/03. As alterações negociadas entre os senadores (da oposição e da base aliada) e o Governo compuseram o texto da PEC 77/03, aprovada em segundo turno, no Senado Federal, por unanimidade, em 17 de 
dezembro de 2003, mas enviada à Câmara dos Deputados. Fazia parte do acordo uma rápida aprovação pela Câmara dos Deputados, preferencialmente sem mudanças. Não foi, contudo, o que se observou. A matéria foi aprovada na Câmara dos Deputados em 16 de março de 2005, na forma de substitutivo (novo texto), e retornou ao Senado Federal.

Mais uma vez, adotou-se o fatiamento. Parte do texto proveniente da Câmara foi aprovada pelo Senado, tornando-se a Emenda Constitucional no 47, de 5 de julho de 2005. Outra parte formou nova proposta de emenda à Constituição, aprovada pelo Senado e remetida à Câmara para deliberação. A EC 47/05 é uma espécie de ajuste, ou complemento, da $\mathrm{EC} 41 / 03$. Tanto assim que os efeitos da $\mathrm{EC} 47 / 05$ retroagem à data de início de vigência da EC 41/03 (art. $6^{\circ}$ da EC 47/05).

Transição: paridade no art. $6^{\circ}$ da EC $41 / 03$

De início, vale lembrar que a EC 41/03 deu aos servidores duas opções de regra de transição, dispostas em seus arts. $2^{\circ}$ e $6^{\circ}$. Nesta última opção, estava garantida a integralidade, mas a revisão se daria "na mesma proporção e na mesma data, sempre que se modificar a remuneração dos servidores em atividade, na forma da lei [...]" (parágrafo único do art. $6^{\circ}$ da EC 41/03). Este parágrafo foi suprimido pela EC 47/05 (art. $5^{\circ}$ ).

Em substituição, o art. $2^{\circ}$ da EC 47/05 garante a paridade entre ativos e aposentados para o servidor que se aposentar pelas regras do caput do art. $6^{\circ}$ da EC 41/03. Com isso, elimina a dúvida gerada pela redação anterior, que excluía o direito dos aposentados à extensão de todos os benefícios e vantagens concedidas aos ativos. Essa alteração foi benéfica e extremamente importante para os servidores em atividade na época da publicação da EC 41/03, que passaram a ter, se aposentados na forma do art. $6^{\circ}$ da EC 41/03, combinado com o art. $2^{\circ}$ da EC 47/05, direito à integralidade e à paridade.

\section{Transição: nova opção}

A EC 47/05 criou, ainda, uma nova opção de transição, com proventos integrais, para os servidores que tenham ingressado no serviço público até a data de publicação da Emenda $\mathrm{n}^{\circ}$ 20, de 16 de dezembro de 1998 (art. $3^{\circ}$ da EC 47/05). As condições cumulativas para aposentadoria, nessa opção, são as seguintes: a) vinte e cinco anos de efetivo exercício no serviço público, quinze anos de carreira e cinco anos no cargo em que se der a aposentadoria; b) trinta e cinco anos de contribuição, se homem, e trinta anos de contribuição, 
se mulher; e c) para cada ano de contribuição que exceder esse mínimo, abate-se um ano da idade da regra permanente (sessenta anos, se homem, e cinqüenta e cinco anos, se mulher).

Portanto, o tempo de contribuição mais a idade devem somar 95, se homem, ou 85 , se mulher, para que o servidor ou a servidora possa usufruir dessa opção de aposentadoria. Com isso, beneficiam-se aqueles que começaram a trabalhar ainda jovens e que tenham elevado tempo de contribuição (antigo tempo de serviço), o que prestigia o princípio da proporcionalidade. Nesse caso, além da integralidade, a EC 47/05 assegura a paridade entre aposentados e ativos. Adicionalmente, estende a paridade para as pensões dos servidores falecidos que tenham se aposentado por essa opção (parágrafo único do art. $3^{\circ}$ da Emenda). A regra suaviza as regras de transição da EC 41/03, em prol dos servidores públicos em processo de aquisição do direito à aposentadoria.

\section{Teto de remuneração}

Houve intensa discussão a respeito do teto de remuneração nos estados e municípios. Esse foi, provavelmente, o tema de maior polêmica nas deliberações da Emenda. O texto inicialmente proposto pelo Senado previa a possibilidade de se estipular como teto, nos estados, Distrito Federal, e municípios, um "valor de referência", mediante lei de iniciativa do Poder Executivo, cujo valor deveria ser, no mínimo, equivalente ao subsídio do chefe do Executivo e, no máximo, igual ao subsídio do desembargador do respectivo Tribunal de Justiça (nova redação do inciso XI do art. 37). Isso se justificaria pelo fato de que em vários estados e municípios a remuneração do chefe do Executivo é reduzida, o que causaria achatamento do teto de diversas carreiras.

Essa idéia não obteve êxito junto à Câmara dos Deputados. Sob forte pressão, essa Casa preferiu incluir no teto do Poder Judiciário estadual e do Distrito Federal os delegados de polícia, os advogados e os agentes fiscais tributários organizados em carreira. Ao retornar a matéria para o Senado Federal, foi a vez de os policiais e bombeiros militares dos estados e do Distrito Federal pressionarem para também serem contemplados no rol das chamadas “carreiras jurídicas", às quais se aplicaria o teto do Judiciário nos estados. Mas o Senado não modificou o texto, sobretudo porque isso implicaria o retorno da PEC à Câmara. O Senado Federal preferiu excluir do texto qualquer modificação do inciso XI do art. 37. Ou seja, não vingou nem o texto inicialmente proposto, nem o aprovado na Câmara dos Deputados. Eis mais uma característica do "fatiamento": se uma Casa suprime uma parte de PEC já aprovada 
pela outra, pode-se encaminhar o texto à promulgação, sem que conste, evidentemente, a parte rejeitada. Foi o que ocorreu.

Com isso, a EC 47/05 restringiu-se, em matéria de teto de remuneração, a incluir dois parágrafos no art. 37 da Constituição. O novo $\S 11$ dispõe que não serão computadas no teto as parcelas de caráter indenizatório, previstas em lei. Embora esclarecedora, a ressalva parece meramente declaratória, pois a natureza dessa parcela já levava a essa conclusão. Acrescenta o art. $4^{\circ}$ da EC 47/05 que enquanto não editada a referida lei, não será computada, para efeito do teto, qualquer parcela de caráter indenizatório definida pela legislação em vigor na data de publicação da EC 41/03.

Por sua vez, o $\S 12$ do art. 37 faculta aos estados e ao Distrito Federal fixar, em seu âmbito, mediante emenda às respectivas constituições e lei orgânica, como teto para todos os poderes, o subsídio mensal dos desembargadores do respectivo Tribunal de Justiça, limitado a noventa inteiros e vinte e cinco centésimos por cento do subsídio mensal dos Ministros do Supremo Tribunal Federal, excetuando-se desse limite os subsídios dos deputados estaduais e distritais e dos vereadores. De modo distinto, essa regra resolve o problema que o Senado tentara superar com o "valor de referência", qual seja, a possibilidade das carreiras do Poder Executivo sofrerem grave limitação de seus rendimentos, pela aplicação do teto com base em baixos subsídios (politicamente determinados) do governador. Não há, solução, porém, se o problema ocorrer na esfera municipal.

\section{Contribuição previdenciária de portadores de doença incapacitante}

Mediante inclusão de novo parágrafo no art. 40, estipula-se um maior limite de isenção à contribuição previdenciária para o beneficiário que, na forma da lei, for portador de doença incapacitante. Neste caso, a contribuição incidirá apenas sobre as parcelas de proventos de aposentadoria e pensão que superem o dobro do limite máximo dos benefícios

do RGPS, o que resultará em redução substantiva de seu valor. É medida de justiça, em vista da condição do beneficiário.

Aposentadoria especial: portadores de deficiência e atividades de risco

A EC 47/05 promove modificação tanto no regime dos servidores públicos (RPPS) quanto no regime geral (RGPS), para permitir que, no caso dos portadores de 
deficiência, sejam adotados requisitos e critérios diferenciados para concessão de aposentadoria, na forma de leis complementares.

No RPPS, os requisitos e critérios diferenciados também são admitidos, nos casos definidos por leis complementares, nos casos em que os servidores: exerçam atividade de risco; ou cujas atividades sejam exercidas sob condições especiais que prejudiquem a saúde ou a integridade física (art. 40, § 4).

No regime geral, não está presente a hipótese de atividades de risco, ou seja, além dos portadores de deficiência, a aposentadoria diferenciada somente é admitida nos casos de atividades exercidas sob condições especiais que prejudiquem a saúde ou a integridade física, nos termos definidos por lei complementar (art. 201, $\left.\S 1^{\circ}\right)$.

\section{RGPS: Alíquotas e bases de cálculo diferenciadas}

A EC 47/05 inclui duas novas hipóteses nas quais a contribuição social do empregador, da empresa e da entidade a ela equiparada, na forma da lei, pode ter alíquotas ou bases de cálculo diferenciadas. Desde a EC 20/98, isso somente poderia se dar em razão da atividade econômica ou da utilização intensiva da mão-de-obra. Agora, também pode ocorrer em virtude do porte da empresa ou da condição estrutural do mercado de trabalho.

\section{Inclusão previdenciária}

A EC 47/05 altera o sistema de inclusão previdenciária previsto pela EC 41/03. Retira a proibição de que os segurados do sistema aposentem-se por tempo de contribuição e nele inclui "aqueles sem renda própria que se dediquem exclusivamente ao trabalho doméstico no âmbito de sua residência, desde que pertencentes a famílias de baixa renda, garantindo-lhes acesso a benefícios de valor igual a um salário-mínimo" (art. 201, § 12). Firma, ainda, que o sistema especial de inclusão previdenciária "terá alíquotas e carências inferiores às vigentes para os demais segurados do regime geral de previdência social" (art. 201, § 13). Com isso, o sistema de inclusão previdenciária, tão logo regulado por lei, poderá estender a proteção previdenciária a milhões de brasileiros.

A disposição não constava da proposta do Governo Lula, tendo sido inserido na reforma pelo Congresso Nacional. O sistema pretende incorporar à previdência, principalmente, os informais e as donas de casa, de baixa renda. Os números variam, mas as estimativas são de que a maioria dos trabalhadores não está filiada ao sistema previdenciário. Para Pastore (2003, p. 91), quase 60\% dos brasileiros ocupados não possui vínculo com a 
previdência. São cerca de 45 milhões de pessoas, das quais 19 milhões são empregados não registrados, 15 milhões trabalham por conta própria, 6 milhões trabalham sem remuneração, 4 milhões são empregados domésticos sem registro em carteira, e 1 milhão são empregadores.

Todo esse contingente, em especial a parcela de baixa renda, está exposto aos riscos sociais do trabalho e não tem proteção atual ou futura para a inatividade. A disposição vem no sentido da recomendação de Soares (2003, p. 133), de que é preciso ir além da perspectiva do seguro baseado no mercado formal de trabalho, pois os 'não incorporáveis' ou 'não incluídos' representam a maioria da população. A medida, se efetivamente implementada, terá grande impacto social e poderá significar um resgate da integração da previdência na seguridade social. Vislumbra-se, contudo, a oposição de entraves econômicos e financeiros à sua implantação, pois o sistema deverá ter alíquotas e carências inferiores às vigentes para os demais segurados do RGPS.

\section{Considerações finais}

A Reforma Previdenciária de iniciativa do Governo Lula teve, expressamente, o intuito de convergência das regras dos regimes dos trabalhadores celetistas e dos servidores públicos. Isso foi apresentado como forma de obter uma previdência social mais justa, equânime e viável financeiramente. Até então, as diferenças entre os regimes dos empregados celetistas e dos servidores públicos eram marcantes. Entre elas, pode-se apontar o fato de que o benefício no RGPS era calculado pela média aritmética simples das remunerações correspondentes a oitenta por cento de todo o período contributivo, multiplicada pelo fator previdenciário, enquanto no RPPS o benefício correspondia à última remuneração do cargo efetivo (integralidade). Também a forma de reajuste era diferenciada, pois os beneficiários do RGPS contavam apenas com a correção monetária, enquanto os servidores públicos tinham suas aposentadorias e pensões vinculadas aos planos de carreira dos ativos (paridade).

Por isso, a Reforma Previdenciária do Governo Lula acabou resultando, basicamente, em medidas voltadas para mudanças nos valores e critérios de acesso aos benefícios de aposentadorias e pensões dos servidores públicos. Assim, centrou fogo no fim da integralidade e da paridade, substituindo-a por um cálculo a ser regulado por lei, mas que levará em conta as remunerações utilizadas como base para as contribuições do servidor aos regimes pelos quais passou (RPPS e RGPS). Aqui dois outros fatores devem ser lembrados, para entender o escopo dessa medida. O primeiro é que, muitas vezes, o trabalhador atua na iniciativa privada antes de ser admitido no serviço público. Na União, por exemplo, o tempo 
médio de serviço anterior à entrada no regime próprio era de 11,7 anos, conforme a Exposição de Motivos $n^{\circ}$ 29/2003. Um segundo aspecto é que as contribuições ao RGPS se dão sobre um teto, o que limita o valor recolhido durante o tempo de CLT. Tudo isso não era levado em conta na aposentadoria do servidor público, que tinha garantido, na inatividade, a última remuneração do cargo efetivo. Em compensação, o servidor contribui na atividade em percentual de $11 \%$ sobre sua remuneração bruta.

O caso das pensões segue o raciocínio da unificação. Aqui, a reforma foi até mais rigorosa, ao estipular que o valor terá abatimento de $30 \%$ da parcela que exceder o valor limite de benefício do RGPS. Ou seja, os sistemas estão equiparados até esse valor limite, já que no regime geral não há abatimento. Para o pensionista de servidor público, se a pensão superar esse valor, incide o desconto.

Também a celeuma criada em torno da contribuição dos atuais inativos e pensionistas terminou por contribuir para a unificação dos regimes. Ao final, não vingou nem a regra proposta pelo Executivo, de isenção no limite do imposto de renda, nem a regra estipulada pelo Congresso Nacional, diferenciada para a União e para os estados, Distrito Federal e municípios. Acabou se firmando constitucional uma terceira opção, estipulada na regra permanente, pela qual a contribuição incide na parcela que superar o limite máximo de benefício fixado para o RGPS.

A unificação, entretanto, fez-se pelo sacrifício de expectativas de direitos dos servidores públicos e com possíveis prejuízos para as carreiras do setor público. A integralidade, a paridade e outras variáveis eram atrativos para a carreira pública, nela mantendo pessoal especializado, que via nesses fatores motivos para não migrar para a iniciativa privada.

Frise-se, porém, que o Brasil não está sozinho nessa tendência. Relata Pinheiro (2003, p. 85-89) que grande número de países realizou ou está em vias de promover reformas que promovam a convergência entre os regimes dos servidores públicos e dos trabalhadores privados, por meio da unificação dos regimes ou da homogeneização das regras. Para o autor, tal convergência é um objetivo desejável e deve ser perseguido a longo prazo. Os sistemas unificados ou homogêneos são mais baratos, justos e transparentes e tem maior possibilidade de viabilidade financeira e atuarial. Esse processo, mostra a experiência internacional, deve vir acompanhado do desenvolvimento e fortalecimento da previdência complementar.

Neste sentido, pode-se vislumbrar, na reforma brasileira, a construção de um modelo único de previdência social no setor público, adicionado pela previdência privada, de natureza complementar. Embora essa sistemática pareça conduzir a uma maior justiça 
previdenciária, poderá levar a distorções, se houver o achatamento dos benefícios unificados no setor público, o que resultaria no fortalecimento induzido do setor privado.

Artigo recebido em agosto de 2006

Aceito em setembro de 2006

\section{Referências}

AMARO, Meiriane Nunes. O processo de reformulação da Previdência Social Brasileira (1995-2004). Brasília: Senado Federal, Consultoria Legislativa, Textos para discussão $\mathrm{n}^{\mathrm{o}} 3$, fev. 2004.

BARROSO, Luís Roberto. Constitucionalidade e legitimidade da Reforma da Previdência (ascensão e queda de um regime de erros e privilégios). In: TAVARES, Marcelo Leonardo (org.). Reforma da Previdência Social: Temas polêmicos e aspectos controvertidos. Rio de Janeiro: Lumen Juris, 2004, p. 49-107.

BERZOINI, Ricardo. Previdência Social: a mudança com justiça e respeito. In: MORHY, Lauro (org.). Reforma da Previdência em Questão. Brasília: UnB, 2003, p. 19-25.

BOSCHETTI, Ivanete. A "Reforma" da Previdência e a Seguridade Social Brasileira. In: MORHY, Lauro (org.). Reforma da Previdência em Questão. Brasília: UnB, 2003, p. 27 47.

BRASIL. Constituição (1988). Texto atualizado até a Emenda Constitucional no 52, de 2006. Disponível em <http://www.presidencia.gov.br>. Acesso em 15 ago. 2006.

BRASIL. Ministério da Previdência Social e Casa Civil da Presidência da República. Exposição de Motivos Interministerial no 29-MPS/CCIVIL-PR. 23 abr. 2003. Disponível em $<$ http://www.presidencia.gov.br $>$. Acesso em 15 ago. 2006.

BRASIL. Supremo Tribunal Federal. Medida cautelar na ação direta de inconstitucionalidade (ADIn-MC) $n^{\circ}$ 2.010/DF. Requerente: Conselho Federal da Ordem dos Advogados do Brasil. Requeridos: Presidente da República e Congresso Nacional. Relator: Ministro Celso de Mello. Tribunal Pleno. Brasília, 30 de setembro de 1999. Disponível em $<$ http://www.stf.gov.br $>$. Acesso em 15 ago. 2006.

BRASIL. Supremo Tribunal Federal. Nota à imprensa. Brasília, 5 de fevereiro de 2004a. Disponível em <http://www.stf.gov.br>, seção Notícias. Acesso em 15 ago. 2006.

BRASIL. Supremo Tribunal Federal. Ação direta de inconstitucionalidade (ADIn) $n^{o}$ 3.105/DF. Requerente: Associação Nacional dos Membros do Ministério Público. Requerido: Congresso Nacional. Relator para o Acórdão: Ministro Cezar Peluso. Tribunal Pleno. Brasília, 18 de agosto de 2004b. Disponível em <http://www.stf.gov.br>. Acesso em 15 ago. 2006. 
BRASIL. Supremo Tribunal Federal. Mandado de Segurança (MS) no 24.875. Impetrantes: Djaci Alves Falcão e outros. Impetrado: Presidente do Supremo Tribunal Federal. Relator: Ministro Sepúlveda Pertence. Brasília, 11 de maio de 2006. Disponível em $<$ http://www.stf.gov.br>, seção Notícias. Irredutibilidade de salário garante manutenção de vantagem pessoal, entende STF. Acesso em 15 ago. 2006.

GUERZONI FILHO, Gilberto. Eficiência Política, Consistência Atuarial e Ajuste Fiscal: Comentários sobre a Emenda $n^{\circ}$ 41/03. In: MODESTO, Paulo (org.). Reforma da Previdência: análise e crítica da Emenda Constitucional $n^{\mathbf{0}}$ 41/2003. Belo Horizonte: Fórum, 2004, p. 147-183.

MIRANDA, Sérgio. A Reforma da Previdência: mudança de modelo e desmonte do Estado. In: MORHY, Lauro (org.). Reforma da Previdência em Questão. Brasília: UnB, 2003, p. 137-155.

MODESTO, Paulo. Reforma da Previdência e Regime Jurídico da Aposentadoria dos Titulares de Cargo Público. In: (org.). Reforma da Previdência: análise e crítica da Emenda Constitucional no 41/2003. Belo Horizonte: Fórum, 2004, p. 21-105.

MONTEIRO NETO, Armando de Queiroz. A Reforma da Previdência como Instrumento de Desenvolvimento Econômico. In: MORHY, Lauro (org.). Reforma da Previdência em Questão. Brasília: UnB, 2003, p. 215-233.

PASTORE, José. Como reduzir a informalidade. In: MORHY, Lauro (org.). Reforma da Previdência em Questão. Brasília: UnB, 2003, p. 91-101.

PINHEIRO, Vinícius Carvalho. Previdência complementar para servidores públicos: pontos polêmicos. In: MORHY, Lauro (org.). Reforma da Previdência em Questão. Brasília: UnB, 2003, p. 49-57.

Unificação de regimes de previdência dos servidores públicos e trabalhadores privados: experiência internacional. In: MORHY, Lauro (org.). Reforma da Previdência em Questão. Brasília: UnB, 2003, p. 83-90.

SOARES, Laura Tavares. Retomando o debate da Reforma da Previdência Social. In: MORHY, Lauro (org.). Reforma da Previdência em Questão. Brasília: UnB, 2003, p. 117 136.

VIANNA, Maria Lúcia Teixeira Werneck. O silencioso desmonte da Seguridade Social no Brasil. In: BRAVO, M.I.S \& PEREIRA, P. (orgs.). Política Social e Democracia, Rio de Janeiro: Cortez/UERJ, 2001, p. 173-195. 


\section{Resumo}

O presente artigo tem por objetivo descrever e analisar a Reforma Previdenciária empreendida pelo Congresso Nacional por iniciativa do Governo Lula, efetivada pelas Emendas Constitucionais $\mathrm{n}^{\text {os }} 41$, de 2003, e 47, de 2005. São examinados em detalhes os efeitos das modificações promovidas no sistema previdenciário brasileiro. A Reforma, tal como a que a antecedeu, não considerou a previdência social de forma integrada à seguridade social. Sua forma final acentuou a configuração de um modelo misto, com um limite de benefícios no sistema público, a partir do qual deve-se recorrer ao sistema privado complementar. No sistema público, a Reforma atuou na tendência de unificação de regras entre os regimes geral e próprio dos servidores públicos.

Palavras-chave: previdência social. seguridade social. reforma constitucional.

\section{Abstract}

This article describes and analyzes the Constitutional Amendments (No. 41, 2003 and No. 47, 2005), which changed the social security system proposed by President Lula and approved by National Congress. The effects of the Amendments in the social security system are examined in details. The Amendments, as well as those preceding them (No. 20, 1998), did not consider the social security system as an integrated component of social welfare. Instead, they established a mixed model, with limited benefits in the public system, resulting in a need for complementation with private systems. In the public system, the Amendments attempted to unify the rules of general administration and those of administration for civil servants.

Key words: social security. social welfare. constitutional amendment. 